\title{
The association of neighborhood racial mix and ED visit count in a cohort of patients on hemodialysis
}

\author{
Ladan Golestaneh ${ }^{1 *}$, Atessa Farzami ${ }^{1}$, Chikeluba Madu$^{2}$, Tanya Johns ${ }^{1}$, Michal L. Melamed ${ }^{1}$ and Keith C. Norris ${ }^{3}$
}

\begin{abstract}
Background: Neighborhood racial mix is associated with dialysis facility performance metrics and mortality outcomes in patients on hemodialysis. We explored the association of neighborhood racial mix with emergency department (ED) visits in patients receiving hemodialysis.

Methods: Using Looking Glass (Montefiore's clinical database) we identified a cohort of patients on hemodialysis with an index ED visit at any of 4 Montefiore Hospital locations, between January 2013 and December 2017 and followed it for number of ED visits through December of 2017 or dropout due to death. The racial mix data for the Bronx block group of each subject's residence was derived from the Census Bureau. We then used negative binomial regression to test the association of quintile of percent of Black residents per residential block group with ED visits in unadjusted and adjusted models. To adjust further for quality offered by local dialysis facilities, with the facility zip code as the locus, we used data from the "Dialysis Compare" website.

Results: Three thousand nine-hundred and eighteen subjects were identified and the median number of ED visits was 3 (interquartile range (IQR) 1-7) during the study period. Subjects living in the highest quintile of percent Black residents were older, more commonly female and had lower poverty rates and higher rates of high school diplomas. Unadjusted models showed a significant association between the highest quintiles of Black neighborhood residence and count of ED visits. Fully adjusted, stratified models revealed that among males, and Hispanic and White subjects, living in neighborhoods with the highest quintiles of Black residents was associated with significantly more ED visits ( $p$-trend $=0.001,0.02,0.01$ respectively). No association was found between dialysis facility locations' quintile of Black residents and quality metrics.
\end{abstract}

Conclusions: Living in a neighborhood with a higher percentage of Black residents is associated with a higher number of ED visits in males and non-Black patients on hemodialysis.

Keywords: Hemodialysis, Emergency department visits, Racial mix, Neighborhood, Disparities, End-stage kidney disease

\section{Background}

The association of health outcomes with neighborhood residence has long been described as an important manifestation of racial segregation in the US [1-5]. Disparities in access to optimal healthcare services are cited as reasons for poor health outcomes, while other reasons relate to lack of neighborhood resources to support healthy

\footnotetext{
*Correspondence: Igolesta@montefiore.org

${ }^{1}$ Albert Einstein College of Medicine / Montefiore Medical Center, 3411

Wayne Ave, Suite 5H, Bronx, NY 10467, USA

Full list of author information is available at the end of the article
}

habits and diets, exposure to crime and environmental toxins, and limited access to high quality outpatient care coordination $[1,5]$. Whether these disparities are related to socioeconomic disadvantages in predominantly Black or Hispanic neighborhoods, institutional/structural racism inherent in political and social systems, and/or local healthcare practices is a point of controversy [5-9]. It is difficult to separate socioeconomic disadvantage from the racial/ethnic makeup of most metropolitan neighborhoods. Therefore, socioeconomic and race/ethnicity

(c) The Author(s). 2019 Open Access This article is distributed under the terms of the Creative Commons Attribution 4.0 International License (http://creativecommons.org/licenses/by/4.0/), which permits unrestricted use, distribution, and 
factors as they relate to health outcomes are frequently clumped together $[1,4]$.

Neighborhood characteristics determine health outcomes in the end-stage kidney disease (ESKD) population as well $[8,10-15]$. Black and White patients that receive care in dialysis facilities located in neighborhoods with a higher percentage of Black residents are less likely to meet performance benchmarks as defined by the Centers for Medicare Services (CMS) [16]. Furthermore, there are higher rates of hospitalizations in patients from dialysis facilities located in areas with a higher percentage of Black residents [16]. Black patients have lower rates of access to pre-ESKD care by a nephrologist, are less likely to have a fistula as the first dialysis access, and have lower rates of referral to transplant centers, which explains some of these outcomes [16, 17]. This is of particular interest because despite these disadvantages, Black patients on hemodialysis have longer adjusted survival time as compared to Whites [16, 18-20]. CMS had proposed adjusting for case mix based on neighborhood characteristics when calculating benchmarks for standardized readmission ratios as part of the quality incentive program. However, when adjusted for a composite neighborhood score (ADI: area deprivation index) the readmission rates studied by CMS were not altered to a degree that they felt warranted altering the existing case mix formula and as a result, neighborhood characteristics were left out of benchmark determinations [21].

In this study, we explore the association of neighborhood racial/ethnic make-up, with subjects' residence as the locus for the census block group, with emergency department (ED) visits in a cohort of patients on hemodialysis that live in the Bronx. We hypothesize that the neighborhood racial/ethnic makeup alone, independent of socio-economic status, is not associated with ED visits. To reduce residual confounding we did a separate analysis, wherein we evaluated the association of neighborhood racial/ethnic make-up with dialysis facility characteristics.

\section{Methods}

The study was approved by the Albert Einstein Institutional Review Board. We adhered to the Declaration of Helsinki in our methods.

\section{Sources of data}

Using Looking Glass ${ }^{\mathrm{T}}$, we identified a cohort of patients on hemodialysis who had an index ED visit between 2013 and $2017(1 / 1 / 2013-1 / 1 / 2017)$, at any of four Montefiore Hospitals in the Bronx, NY. Looking Glass ${ }^{\mathrm{Tm}}$ Clinical Analytics (Streamline Health, Atlanta, Georgia) is a software application developed at Montefiore to help build a clinical database. It integrates clinical and administrative datasets to identify the specific patient cohorts and allows for retrospective measurement of our outcome [22, 23]. We included only adult patients (age > 21) who were receiving maintenance hemodialysis, with a mix of incident and prevalent hemodialysis patients. The cohort was identified using ICD 9 and 10 codes for ESKD, transplant recipients were excluded using ICD 9 and 10 codes (including those returning to dialysis) while patients on peritoneal dialysis (PD) were excluded using PD billing codes (Fig. 1). For this analysis we excluded all ED visits that led to hospital admissions, choosing instead to focus on ED visits that did not lead to an admission [22]. We linked subject level variables and American Community Survey (ACS) data (percent Black, percent living under the poverty line, percent graduated from high school) by using subjects' home addresses as the locus of the block group. We used the United States Census Bureau, 2012-2016 ACS 5-Year Estimates to obtain neighborhood characteristics [24] (Fig. 1). There were 954 block groups in the Bronx. Compared to those that had a census linked block group, those subjects that did not $(n=683)$ were slightly younger (mean age 58.0 years (standard deviation (SD) 15.6)), had the following racial/ethnic breakdown: Whites 83 (11.7\%), Blacks 311 (43.9\%), Hispanics 250 (35.3\%) and "other" 65 (9.2\%), and were more commonly male $(428(60.4 \%))$. Our sample size had missing data points for the body mass index variable (526 missing) representing $<15 \%$ of the total data points, with the missingness completely at random, as tested by Little's MCAR test. Therefore a multiple imputation strategy was not used [25].

\section{Dialysis facility data}

We did a separate analysis to evaluate differences in quality of dialysis delivery between dialysis facilities located in the Bronx. We used the "Dialysis Compare" database provided by CMS to identify the location, ownership and performance on CMS selected quality measures. We linked ACS indicators to the census tract for each dialysis facility address using the "geocoding" application. We then analyzed the association of dialysis facility block group attributed percent of Black residents, percent living under the poverty line and percent that graduated high school, with CMS reported hospitalization rates for 2016 for that facility, and five star ratings reported by each facility to CMS for the year 2016.

\section{Primary exposure}

We categorized our exposure variable, percent Black residents in a block group, into quintiles for the final analysis as follows: $1=1.0-19.1 \%$ (reference group); $2=$ $19.2-29.3 \% ; \quad 3=29.5-45.8 \%, \quad 4=46.4-68.9 \% ; \quad 5=69.3-$ $100 \%$. 


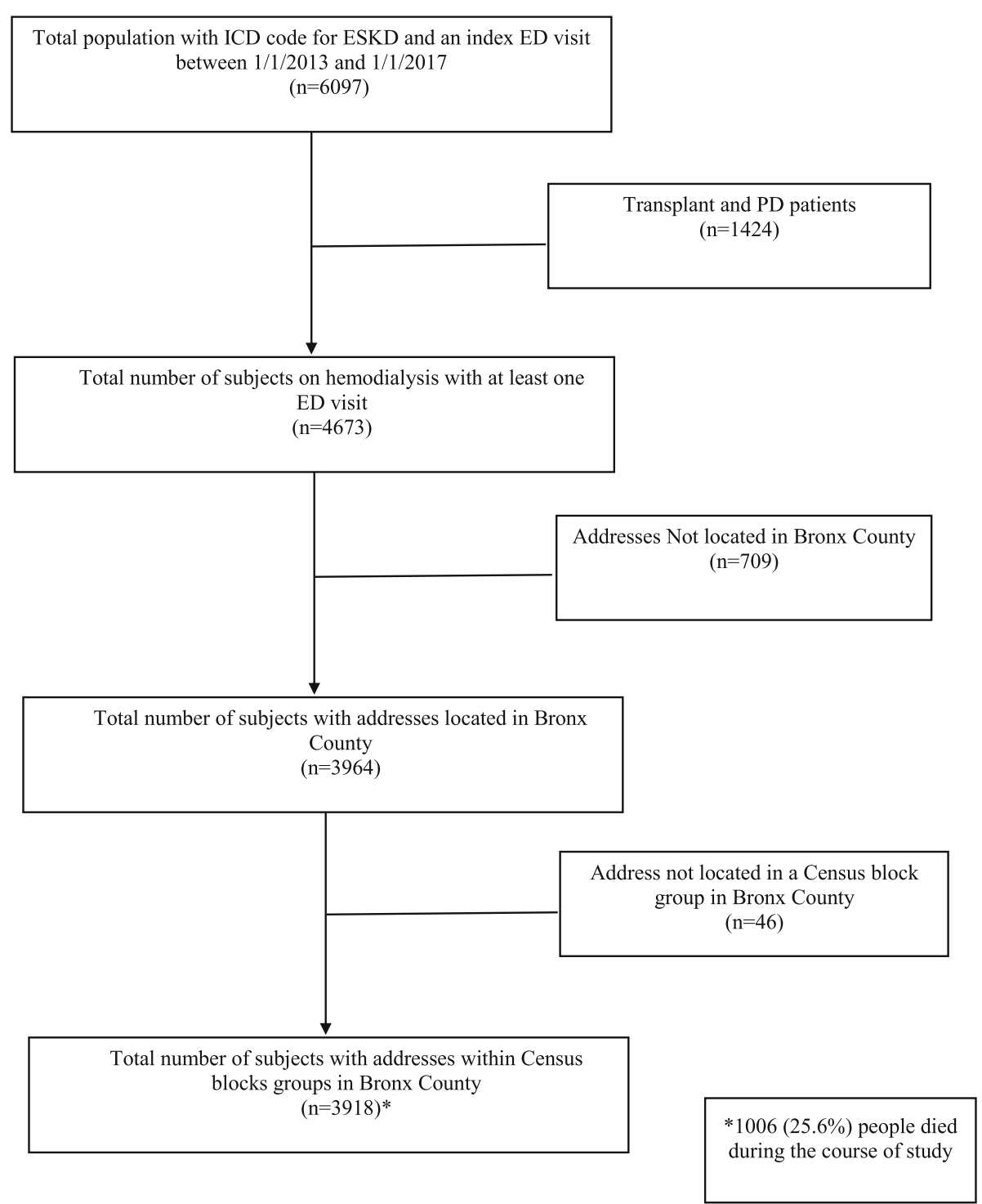

Fig. 1 Study Flow Chart

\section{Primary outcome}

We obtained longitudinal data on ED visits until the end of the study period or death event. We excluded all ED visits that led to hospital admissions, choosing instead to focus on ED visits that did not lead to an admission. Previous studies have shown a strong association between previous ED visits and repeat ED utilization, demonstrating a pattern of behavior in response to lack of outpatient engagement [26-28].

\section{Covariates}

Patient-level covariates included: 1- demographic (age, sex, race, ethnicity, socioeconomic status, primary language (English vs not-English), marital status, type of residence (skilled nursing facility (SNF) vs non- SNF) and insurance status (Commercial, Medicaid, Medicare), and 2- clinical/anthropomorphic (Charlson score, presence of permanent catheter (permcath)) for dialysis, dialysis relevant laboratory values that are validated prognostic markers included minimum albumin within 90 days around index ED visit, lowest and highest serum phosphorus levels within 90 days around index ED visit, lowest and highest hemoglobin (Hgb) levels within 90 days around index ED visit, minimum body mass index (BMI) within 90 days around index ED visit, history of diabetes mellitus (defined as HgbA1c $>6.0 \%$ or an ICD diagnosis of diabetes mellitus within 1 year prior to index ED visit), and history of heart failure (defined as any ICD diagnosis associated with heart failure within 1 year prior to index ED visit). The Charlson score was calculated by Looking Glass based on ICD codes [29] (Additional file 1). Individual socio-economic status 
(SES), is represented by Looking Glass after it is derived from Census Bureau Tract data and the results represent the standard deviation above or below New York State's mean income [3].

\section{Statistical analysis}

We used STATA version 15.0 for all analyses. The association of demographic and clinical variables and quintile of percent of Black residents attributed to block group was tested using one-way ANOVA and Kruskal Wallis tests for continuous variables and Chi-Square or Fisher's exact tests for categorical variables. We used negative binomial regression to test the association of each variable with the outcome: ED visit count. We adjusted this analysis to duration of study follow-up, using date of death as the dropout date. We then built a model using negative binomial regression to test the association of quintile of percent of Black residents with ED visits in our cohort, while adjusting for 1) sociodemographic variables that were significant in bivariate analysis only, and 2) sociodemographic and clinical variables that were significant in bivariate analyses.

We tested the following for interactions with respect to the outcome of ED visits by placing a multiplicative term in the model: quintile of percent Black residents and subjects' SES, quintile of percent Black residents and sex, quintile of percent Black residents and race category of subjects, quintile of percent Black residents and insurance status of subjects. Because of significant interactions found between at least one quintile (\#3) of percent Black residents and sex $(p=0.01)$ as well as quintile (\#3) of percent Black residents and self-identified race (0.02) we stratified all multivariable models based on sex and race.

\section{Results}

\section{Study population}

Six thousand and ninety-seven subjects with a diagnosis of ESKD had made at least one ED visit to any of 4 Montefiore affiliated health facilities in the Bronx. Four thousand six hundred and seventy-three of these were on hemodialysis and 3918 who had complete data on Census Bureau and clinical attributes were identified (Fig. 1). The mean age of the population was 62.2 years (+/-14.8), 1853 (46.7\%) were Black, 1539 (38.8\%) were Hispanic, and 260 (6.6\%) were White (Table 1). Twothousand, two hundred and twenty-six subjects (56.2\%) were male, and 812 (20.5\%) did not speak English as their primary language. The median number of ED visits made by each patient after the index ED visit for the duration of the study period (median: 2.69 years (IQR: 1.36-3.56)) was 3 (interquarile range (IQR) $1-7$ ). The median Charlson score was 5 (IQR 2-7).
Of the block groups examined (in which at least one subject lived) the percent of Black residents ranged from 2.6 to $90.3 \%$ of the block group population, with the median percent Black residents at 36.1\% (IQR: 23.3-60.9\%). Subjects living in the highest quintile of percent Black residents were older and more commonly female. The highest percent Black block groups had fewer Hispanics, and fewer non-English speaking patients on hemodialysis as compared to subjects living in the lower percent Black population quintiles (Table 1). Interestingly, fewer subjects living in the highest percentage of Black neighborhoods in the Bronx were living under the poverty line, and in general this population had a higher percentage of high school graduates and had higher SES (Table 1).

\section{Associations between baseline characteristics and ED visits}

Bivariate analysis showed that the following variables had a significant association with high incidence rate ratios (IRR) of avoidable ED visits: quintiles 4 and 5 of percent Black residents, non-English as primary language, Medicaid insurance, a history of heart failure, a higher Charlson score, and higher maximum phosphorus levels (Table 2). In contrast, being older, living in a SNF, having higher minimum phosphorus, having higher BMI, having higher minimum albumin and having a higher minimum hemoglobin were all significantly protective against an increased IRR for ED visits.

\section{Associations between neighborhood percent black residents and ED visits}

The association between quintile of percent Blacks in the population and repeat ED visits was significant only in men, and addition of socio-demographic and clinical variables to the model strengthened this association (Table 3; Fig. 2). Furthermore, for White patients on hemodialysis, the association with repeat ED visits was robust especially in the quintile 4 and 5 (though not statistically significant in quintile 5) after adjusting for socio-demographic and clinical variables (Table 4). For Hispanic subjects on hemodialysis, the association of increasing quintile (quintiles 4 and 5) of percent Black in the block group with ED visits was significant and strengthened with the addition of socio-demographic and clinical variables, the latter of which suggests a possible mediation effect by these variables.

\section{Associations between neighborhood percent black residents and dialysis facility characteristics}

Twenty-four dialysis facilities were identified, of which 19 (79.1\%) were "for profit". The median hospitalization rate reported by the dialysis facilities to CMS was 1.91 hospitalizations per patient per year (IQR 1.61-2.80) in 
Table 1 Baseline characteristics of the study population

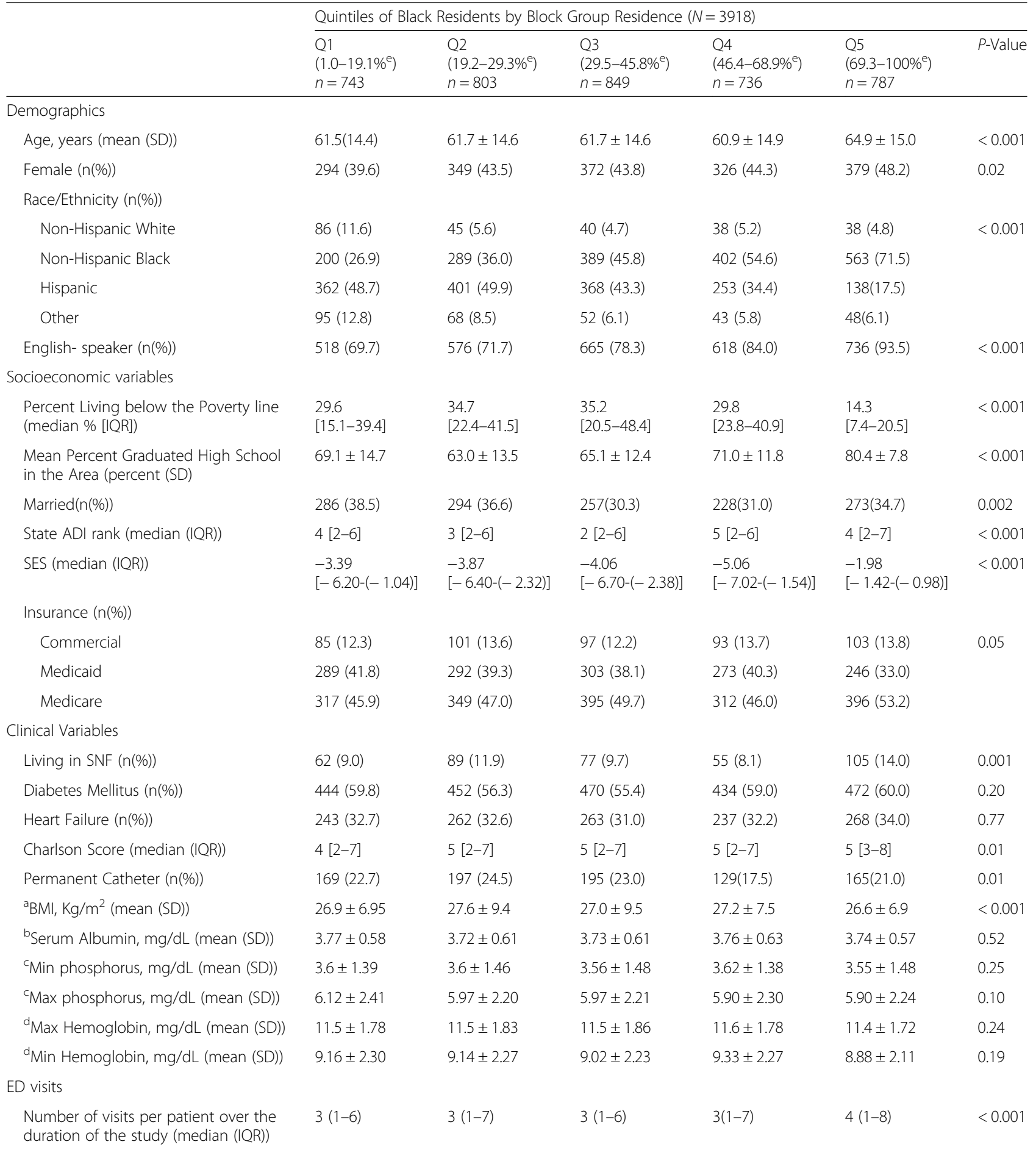

Values for categorical variables are given as count (proportion); values for continuous variables are given as mean \pm standard deviation or median [interquartile range] if skewed

Abbreviations: ADI Area deprivation index, SES Socioeconomic status, BMI Body mass index, SNF Skilled nursing facility, ED Emergency department Complete data available except for the following variables: ${ }^{\mathrm{a}} \mathrm{BMI}(n=3369),{ }^{\mathrm{b}}$ Phosphorus $(n=3336),{ }^{\mathrm{c}} \mathrm{Albumin}(n=3606),{ }^{\mathrm{d}} \mathrm{Hemoglobin}(n=3742)$ eMedian 
Table 2 Association of socio-demographic and clinical variables with Emergency Department (ED) visits

\begin{tabular}{|c|c|c|}
\hline Variable & IRR for number of future ED visits & 95\% confidence Interval \\
\hline \multicolumn{3}{|c|}{ Proportion of Black residents in community $(n=3918)$} \\
\hline Q1 & 1.00 & \\
\hline Q2 & 1.08 & $0.96-1.22$ \\
\hline Q3 & 1.02 & $0.91-1.14$ \\
\hline Q4 & 1.15 & $1.02-1.30$ \\
\hline Q5 & 1.15 & $1.03-1.30$ \\
\hline \multicolumn{3}{|c|}{ Graduated High school $(n=3918)$} \\
\hline Q1 & 1.00 & \\
\hline Q2 & 1.03 & $0.92-1.15$ \\
\hline Q3 & 1.07 & $0.96-1.20$ \\
\hline Q4 & 1.10 & $0.98-1.24$ \\
\hline Q5 & 0.98 & $0.87-1.10$ \\
\hline \multicolumn{3}{|c|}{ \% living under poverty line $(n=3918)$} \\
\hline Q1 & 1.0 & \\
\hline Q2 & 1.06 & $0.94-1.19$ \\
\hline Q3 & 1.15 & $1.02-1.29$ \\
\hline Q4 & 1.15 & $1.02-1.29$ \\
\hline Q5 & 0.96 & $0.86-1.08$ \\
\hline \multicolumn{3}{|l|}{ Age $(n=3964)$} \\
\hline Q1 (reference) & 1 & \\
\hline Q2 & 0.90 & $0.81-1.01$ \\
\hline Q3 & 0.90 & $0.81-1.01$ \\
\hline Q4 & 0.85 & $0.76-0.96$ \\
\hline Q5 & 0.88 & $0.79-0.99$ \\
\hline \multicolumn{3}{|l|}{ Gender $(n=3964)$} \\
\hline Male & 1.0 & \\
\hline Female & 1.07 & $0.99-1.15$ \\
\hline \multicolumn{3}{|l|}{ Race $(n=3964)$} \\
\hline Non-Hispanic White & 1.0 & \\
\hline Non-Hispanic Black & 1.16 & $0.99-1.36$ \\
\hline Hispanic & 1.16 & $0.99-1.35$ \\
\hline Other & 0.96 & $0.78-1.17$ \\
\hline \multicolumn{3}{|l|}{ Language $(n=3964)$} \\
\hline English & 1.0 & \\
\hline Non-English & 1.10 & $1.00-1.20$ \\
\hline \multicolumn{3}{|l|}{ Insurance $(n=3695)$} \\
\hline Commercial & 1.0 & \\
\hline Medicare & 1.06 & $0.95-1.18$ \\
\hline Medicaid & 1.16 & $1.03-1.29$ \\
\hline \multicolumn{3}{|l|}{ Married $(n=3964)$} \\
\hline Not married & 1.0 & \\
\hline Married & 0.93 & $0.86-1.01$ \\
\hline \multicolumn{3}{|l|}{ Lived in SNF $(n=3715)$} \\
\hline No & 1.0 & \\
\hline
\end{tabular}


Table 2 Association of socio-demographic and clinical variables with Emergency Department (ED) visits (Continued)

\begin{tabular}{|c|c|c|}
\hline Variable & IRR for number of future ED visits & 95\% confidence Interval \\
\hline Yes & 0.77 & $0.67-0.88$ \\
\hline \multicolumn{3}{|l|}{ PC use at index ED visit $(n=3964)$} \\
\hline No & 1 & \\
\hline Yes & 1.06 & $0.97-1.16$ \\
\hline \multicolumn{3}{|l|}{ History of DM (3964) } \\
\hline No & 1.0 & \\
\hline Yes & 0.98 & $0.91-1.05$ \\
\hline \multicolumn{3}{|l|}{ History of Heart Failure $(n=3964)$} \\
\hline No & 1.0 & \\
\hline Yes & 1.23 & $1.14-1.33$ \\
\hline Charlson Score & 1.02 & $1.00-1.03$ \\
\hline BMI $(n=3997)$ & 0.99 & $0.98-0.99$ \\
\hline Min phosphorus ( $n=3969$ ) (for every $1 \mathrm{mg} / \mathrm{dL}$ increase in value) & 0.94 & $0.92-0.97$ \\
\hline Max phosphorus ( $n=3969$ ) (for every $1 \mathrm{mg} / \mathrm{dL}$ ) increase in value) & 1.04 & $1.02-1.06$ \\
\hline Min albumin ( $n=3606$ ) (for every $1 \mathrm{~g} / \mathrm{dL}$ increase in value) & 0.87 & $0.81-0.94$ \\
\hline Max Hemoglobin ( $n=3784$ ) (for every $1 \mathrm{~g} / \mathrm{dL}$ increase in value) & 1.01 & $0.99-1.03$ \\
\hline Min Hemoglobin ( $n=3784$ ) (for every $1 \mathrm{~g} / \mathrm{dL}$ increase in value) & 0.93 & $0.92-0.94$ \\
\hline
\end{tabular}

DM Diabetes mellitus, SNF Skilled nursing facility, IRR Incident rate ratio, BMI Body mass index, PC Permacath

2016 (ED visit data were not available). The median Five Star rating of the dialysis facilities was 3 (IQR 3-4). There were no statistically significant associations between percent Black residents, percent of population living under the poverty line, and percent of residents that graduated high school of the block group of each dialysis facility and CMS reported hospitalization outcomes $(p=$ $0.52,0.49$ and 0.80 , respectively). Nor was there any association between percent Black residents, percent of population living under the poverty line, and percent of residents that graduated high school of the block group of each dialysis facility and their Five Star rating $(p=$ $0.25,0.17,0.36$ respectively).

\section{Discussion}

Our study of a cohort of patients on hemodialysis who had at least one ED visit to a large hospital system showed a median IRR of 3 repeat ED visits during the

Table 3 Incident Rate Ratio (IRR) for Emergency Department (ED) visits by quintile of percent black population stratified by sex

\begin{tabular}{lllll}
\hline Sex & $\begin{array}{l}\text { \% Black in the } \\
\text { Block Area }\end{array}$ & $\begin{array}{l}\text { Model 1: } \\
\text { Unadjusted IRR }\end{array}$ & $\begin{array}{l}\text { Model 2: IRR adjusted for socio- } \\
\text { demographic variables }\end{array}$ & $\begin{array}{l}\text { Model 3: IRR adjusted for socio-demographic and } \\
\text { clinical variables }\end{array}$ \\
\hline Male & Q1 & 1.0 (Reference) & 1.0 (Reference) & 1.0 (Reference) \\
& Q2 & $1.07(0.92-1.25)$ & $1.09(0.93-1.27)$ & $1.15(0.97-1.34)$ \\
Q3 & $1.16(1.00-1.35)$ & $1.19(1.02-1.39)$ & $1.29(1.10-1.51)$ \\
Q4 & $1.25(1.07-1.46)$ & $1.28(1.09-1.51)$ & $1.36(1.15-1.61)$ \\
Q5 & $1.20(1.03-1.40)$ & $1.21(1.03-1.42)$ & $1.25(1.05-1.49)$ \\
p-trend & 0.004 & 0.003 & 0.001 \\
Female & Q1 & $1.0($ Reference) & $1.0($ Reference) & 1.0 (Reference) \\
Q2 & $1.07(0.89-1.28)$ & $1.07(0.89-1.29)$ & $1.12(0.92-1.36)$ \\
Q3 & $0.85(0.71-1.02)$ & $0.86(0.72-1.03)$ & $0.89(0.72-1.05)$ \\
Q4 & $1.03(0.86-1.24)$ & $1.04(0.86-1.25)$ & $1.15(0.93-1.39)$ \\
Q5 & $1.08(0.90-1.29)$ & $1.18(0.98-1.42)$ & $1.21(0.97-1.46)$ \\
p-trend & 0.48 & 0.20 & 0.10
\end{tabular}

\footnotetext{
a Adjusted for age, race/ ethnicity, primary language, neighborhood percent poverty, neighborhood percent graduated from high school, percent married, SES, and insurance

${ }^{\mathrm{b}}$ Adjusted for all of above + presence of permcath, residence at skilled nursing facility, Charlson score, minimum Hemoglobin and body mass index within 90 days of index ED visit
} 


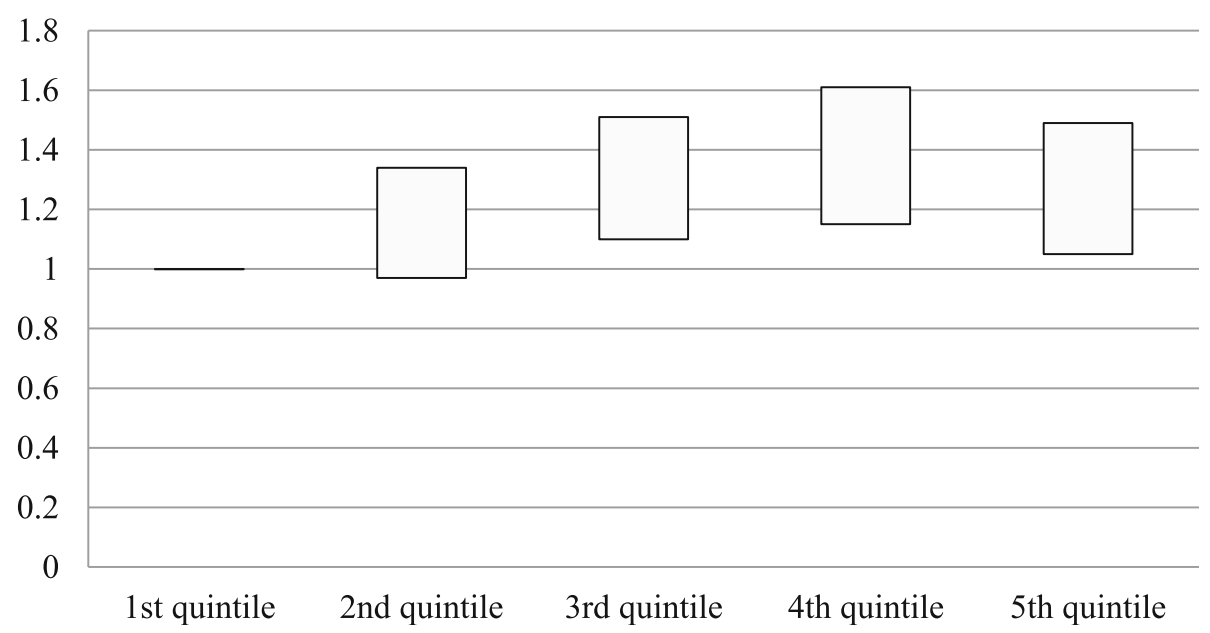

Fig. 2 IRR of Avoidable ED Visit Count and Quintile of Percent Black in Neighborhood of Residence in Male Patients on Hemodialysis

Table 4 Incident Rate Ratio (IRR) for Emergency Department (ED) visits by quintile of percent black population stratified by race/ ethnicity

\begin{tabular}{|c|c|c|c|c|}
\hline Race/Ethnicity & $\begin{array}{l}\% \text { Black in the } \\
\text { Block Area }\end{array}$ & $\begin{array}{l}\text { Model 1: } \\
\text { Unadjusted IRR }\end{array}$ & $\begin{array}{l}\text { Model 2: IRR adjusted for socio- } \\
\text { demographic variables }^{\mathrm{a}}\end{array}$ & $\begin{array}{l}\text { Model 3: IRR adjusted for socio-demographic } \\
\text { and clinical variables }\end{array}$ \\
\hline \multirow{6}{*}{$\begin{array}{l}\text { Non-Hispanic } \\
\text { White (247) }\end{array}$} & Q1 & 1.0 (Reference) & 1.0 (Reference) & 1.0 (Reference) \\
\hline & Q2 & $1.01(0.64-1.60)$ & $0.92(0.59-1.51)$ & $0.94(0.55-1.60)$ \\
\hline & Q3 & $1.29(0.81-2.04)$ & $1.16(0.69-1.94)$ & $1.18(0.68-2.03)$ \\
\hline & Q4 & $1.75(1.12-2.73)$ & $2.09(1.21-3.60)$ & $2.29(1.27-4.12)$ \\
\hline & Q5 & $1.16(0.72-1.83)$ & $1.16(0.72-1.88)$ & $1.31(0.78-2.20)$ \\
\hline & $\mathrm{p}$-trend & 0.07 & 0.09 & 0.02 \\
\hline \multirow{6}{*}{$\begin{array}{l}\text { Non-Hispanic } \\
\text { Black (1842) }\end{array}$} & Q1 & 1.0 (Reference) & 1.0 (Reference) & 1.0 (Reference) \\
\hline & Q2 & $0.97(0.79-1.20)$ & $1.00(0.81-1.23)$ & $1.10(0.87-1.38)$ \\
\hline & Q3 & $1.00(0.82-1.21)$ & $1.00(0.82-1.22)$ & $1.10(0.88-1.36)$ \\
\hline & Q4 & $1.00(0.82-1.22)$ & $1.00(0.82-1.22)$ & $1.10(0.89-1.37)$ \\
\hline & Q5 & $1.04(0.86-1.25)$ & $1.14(0.93-1.39)$ & $1.18(0.95-1.47)$ \\
\hline & $\mathrm{p}$-trend & 0.49 & 0.20 & 0.15 \\
\hline \multirow[t]{6}{*}{ Hispanic (1522) } & Q1 & 1.0 (Reference) & 1.0 (Reference) & 1.0 (Reference) \\
\hline & Q2 & $1.11(0.94-1.30)$ & $1.17(0.99-1.39)$ & $1.22(1.03-1.45)$ \\
\hline & Q3 & $0.93(0.78-1.10)$ & $0.99(0.83-1.17)$ & $1.03(0.86-1.23)$ \\
\hline & Q4 & $1.19(0.99-1.43)$ & $1.24(1.03-1.50)$ & $1.36(1.11-1.69)$ \\
\hline & Q5 & $1.26(1.00-1.58)$ & $1.26(0.99-1.59)$ & $1.37(1.07-1.76)$ \\
\hline & p-trend & 0.07 & 0.06 & 0.01 \\
\hline \multirow[t]{6}{*}{ Other (306) } & Q1 & 1.0 (Reference) & 1.0 (Reference) & 1.0 (Reference) \\
\hline & Q2 & $1.12(0.79-1.59)$ & $1.15(0.79-1.67)$ & $1.13(0.77-1.64)$ \\
\hline & Q3 & $0.97(0.66-1.44)$ & $1.03(0.70-1.51)$ & $0.96(0.63-1.44)$ \\
\hline & Q4 & $1.21(0.82-1.80)$ & $1.29(0.85-1.94)$ & $1.26(0.82-1.95)$ \\
\hline & Q5 & $1.29(0.89-1.89)$ & $1.32(0.89-1.97)$ & $1.18(0.77-1.80)$ \\
\hline & $\mathrm{p}$-trend & 0.17 & 0.16 & 0.52 \\
\hline
\end{tabular}

a Adjusted for age, sex, primary language, neighborhood percent poverty, neighborhood percent graduated from high school, percent married, SES, and insurance ${ }^{\mathrm{b}}$ Adjusted for all of above + presence of permcath, residence at skilled nursing facility, Charlson score, minimum Hemoglobin and body mass index within 90 days of index ED visit 
study period. Living in block groups in the highest quintiles of percent Black residents was associated with an IRR of 4 avoidable ED visits. Hispanic and White subjects that lived in areas with the highest percentage of Black residents had higher IRR of avoidable ED visits than the Black residents, as did male patients on hemodialysis living in areas with the highest percentage of Black residents as compared to female patients. We found that being younger, a non-English speaker, and having a history of heart failure (most likely a proxy for episodes of fluid overload) are also significantly associated with ED visit rates. These results are consistent with other studies in the literature [30,31]. The IRR for ED visits in our study is comparable to national rates, and the differential risks defined by neighborhood of residence is consistent with associations reported between neighborhood of residence and hospitalization outcomes in the ESKD population [4, 5, 27].

The history of racial segregation in America has led to the establishment of what we know today as residentially segregated metropolitan areas and was driven historically by systematic exclusion of Blacks from the two of the most generous and foundational programs for creating wealth and opportunity in the nation, the Homeowners' Loan Act of 1933 which created the Home Owners Loan Corporation (HOLC) and the Servicemen's Readjustment Act of 1944 or GI Bill which supported housing and education [32]. The persistent exclusion beyond civil rights legislation through exclusionary policies and/or practices have maintained segregation and perpetuated socioeconomic and other structural disparities that disproportionately affect predominantly Black neighborhoods [32]. Some contributors to neighborhood level health disparities are high crime rates, limited mobility, low quality schools, sub-standard housing, few recreational facilities and lack of wholesome food options, all of which are compounded by the constant financial and psychological stress of a lower class lifestyle [1]. Patients with ESKD are disproportionately clustered in large metropolitan, predominantly black neighborhoods [15].

An analysis by Rodriguez et al. found White and Black patients on hemodialysis that lived in predominantly Black neighborhoods had worse quality dialysis and longer times to transplant as compared to those who resided in zip codes with lower percentage of Blacks [16]. The mortality rates were higher in the White patients that lived in predominantly Black neighborhoods, as compared to Black patients [16]. Yan et al. showed lowest pre-ESKD nephrology care and arterio-venous fistula placement for young Blacks in metropolitan areas [17]. Within the first year of starting hemodialysis, adjusted cardiovascular and infection related hospitalizations were higher in younger Black and Hispanic patients [33]. In these studies, those neighborhoods with a higher percentage of Black residents also had lower median incomes, a higher percentage of families living under the poverty line and a lower percentage of residents with high school diplomas [3, 16, 33]. By contrast, our analysis of those block groups in the Bronx with the higher percentage of Black residents found fewer families living under the poverty line and with a higher percentage of residents having graduated high school. Our observations highlight demographic differences within racially clustered communities but also across different geographic areas. The finding that despite higher SES those living in predominantly Black neighborhoods had higher ED visit counts could be due to distrust of the medical establishment that has been reported to influence patients' beliefs and behaviors for seeking and/or receiving appropriate care, and ability to achieve equitable clinical outcomes [34, 35]. Another factor could be stereotype threat, a more recently recognized concept in healthcare, that refers to the fear of being judged by, and/or of personally confirming through one's own actions, negative group stereotypes that specifically operate within the domain of healthcare, such as inferior intelligence, lower status, and being less deserving of the highest standard of care, and has been identified to operate in older African Americans [36]. Furthermore, the finding that White and Hispanic patients from neighborhoods with a higher percentage of Black residents were at an even higher risk for avoidable ED visits than Black patients is consistent with social theories that explain the disproportionately bad health outcomes in these populations: positing that Whites and Hispanics who reside in predominantly Black neighborhoods are even more vulnerable than their Black counterparts [5]. Our finding that male patients on hemodialysis are at higher risk for avoidable ED visits in those neighborhoods with a higher percentage of Black residents supports prior data that shows that young Black men are less likely to access primary care and that those on hemodialysis are at higher risk for mortality than their counterparts [10, 37, 38] (Fig. 2).

Limitations of our study include the retrospective nature of the analysis, missing data for some of the clinical variables, as well as the lack of data with respect to dialysis vintage, although there is no reason to suspect that these phenomena should introduce differential bias into the interpretation of results that are based on neighborhood racial makeup. Our cohort excluded patients that never made an ED visit over the study period but previous work shows a high rate of ED visits in this population, therefore we feel comfortable that our sample represents most of the hemodialysis population served by our hospitals [22]. Though Montefiore is the predominant hospital in the Bronx and the fidelity of patients to the location of their recurrent ED visits is high, there is a possibility that a number of patients made ED visits to 
other hospitals in the Bronx and thus were not taken into account. This may introduce differential bias because two of the non-Montefiore hospitals are located in the South Bronx, which has a significantly socioeconomically disadvantaged population, by Bronx standards. However, because of the lower geographic variation in access to care and the availability of outpatient services by the one hospital system studied, residual confounding related to these variables is minimized. Finally we were unable to capture the laboratory data routinely collected at the outpatient dialysis facilities which would have been helpful in interpreting some of this data. Strengths of our analysis included minimal residual confounding related to differences in geographic access to care, hospital related services, and chronic illnesses requiring repeat hospitalizations (as we chose ED visits, with more of an emphasis on patient behavior, family/social support and care coordination, than hospitalizations).

\section{Conclusions}

In conclusion, our study of a cohort of patients on hemodialysis in the Bronx shows that living in a neighborhood with a higher percentage of Blacks is associated with repeat ED visits, especially in males and non-Black patients (Hispanic and White). The implications of these findings support the role of structural and institutional barriers to effective outpatient care for the ESKD population and the fact that they disproportionately affect males living in predominantly Black neighborhoods. In order to mitigate inpatient resource utilization, attention should be paid to upstream barriers to effective outpatient care in predominantly Black neighborhoods and recognize that this affects patients of all backgrounds that live in these communities.

\section{Additional file}

Additional file 1: CLG comorbidity materials. Ad hoc report comorbidity data. The PDF file serves as a reference for the derivation of the comorbidity index score. This was developed by Clinical Looking Glass to serve as an aide and reference for the derivations of the Charlson comorbidity score reported by Looking Glass. (PDF 1315 kb)

\section{Abbreviations}

ACS: American Community Survey; ADI: Area deprivation index; BMI: Body mass index; CLG: Clinical Looking Glass; CMS: Centers for Medicare Services; ED: Emergency department; ESKD: End Stage Kidney Disease; Hgb: Hemoglobin; ICD: International classification of disease; IQR: Interquartile range; IRR: Incident rate ratio; PD: Peritoneal dialysis; Permcath: Permanent catheter; SES: Socio-economic status; SNF: Skilled nursing facility; US: United States
}

\section{Acknowledgements}

We would like to acknowledge Dr. Yungtai Lo, Ph.D. for his assistance with the statistical design of this study. We would like to acknowledge the help of Dr. Colin Rehm for obtaining ACS data.

\section{Authors' contributions}

The following is a summary of each author's contribution to the manuscript: LG conceptualized the hypothesis, procured the clinical database, linked the clinical database to the Census Bureau data, devised the analysis plan and wrote the manuscript. AF procured the block group level data from the Census Bureau, CM helped with research of the Introduction and Discussion, MLM and TJ helped with manuscript writing and references and KCN oversaw the manuscript development and writing. All authors read and approved the final version of this manuscript.

\section{Funding}

This study was supported by a grant from the National Center for Advancing Translational Sciences (NCATS), components of the National Institutes of Health (NIH), through CTSA grant number UL1TR002556-01.

\section{Availability of data and materials}

The study database can be made available upon request.

\section{Ethics approval and consent to participate}

This study was approved by the Albert Einstein College of Medicine Institutional Review Board as an "exempt" study and thus did not require consent. All data have been de-identified.

\section{Consent for publication}

Not applicable.

\section{Competing interests}

The authors declare that they have no competing interests.

\section{Author details}

${ }^{1}$ Albert Einstein College of Medicine / Montefiore Medical Center, 3411 Wayne Ave, Suite 5H, Bronx, NY 10467, USA. ²Albert Einstein College of Medicine, Bronx, NY, USA. ${ }^{3}$ David Geffen School of Medicine at University of California, Los Angeles, Los Angeles, CA, USA.

Received: 24 October 2018 Accepted: 12 August 2019

Published online: 02 September 2019

\section{References}

1. Isaacs SL, Schroeder SA. Class - the ignored determinant of the nation's health. N Engl J Med. 2004;351(11):1137-42.

2. Navarro V. Race or class versus race and class: mortality differentials in the United States. Lancet. 1990;336(8725):1238-40.

3. Diez Roux AV, Merkin SS, Arnett D, et al. Neighborhood of residence and incidence of coronary heart disease. N Engl J Med. 2001;345(2):99-106.

4. Adler NE, Rehkopf DH. U.S. disparities in health: descriptions, causes, and mechanisms. Annu Rev Public Health. 2008;29:235-52.

5. Williams DR, Collins C. Racial residential segregation: a fundamental cause of racial disparities in health. Public Health Rep (Washington, DC: 1974). 2001; 116(5):404-16.

6. Chae DH, Nuru-Jeter AM, Adler NE. Implicit racial bias as a moderator of the association between racial discrimination and hypertension: a study of midlife African American men. Psychosom Med. 2012;74(9):961-4.

7. Hudson DL, Puterman E, Bibbins-Domingo K, Matthews KA, Adler NE. Race, life course socioeconomic position, racial discrimination, depressive symptoms and self-rated health. Soc Sci Med. 2013;97:7-14.

8. Kimmel PL, Fwu CW, Eggers PW. Segregation, income disparities, and survival in hemodialysis patients. J Am Soc Nephrol. 2013;24(2):293-301.

9. Shoham DA, Vupputuri S, Kaufman JS, et al. Kidney disease and the cumulative burden of life course socioeconomic conditions: the Atherosclerosis Risk in Communities (ARIC) study. Soc Sci Med (1982). 2008; 67(8):1311-20.

10. Johns TS, Estrella MM, Crews DC, et al. Neighborhood socioeconomic status, race, and mortality in young adult dialysis patients. J Am Soc Nephrol. 2014; 25(11):2649-57.

11. Volkova N, McClellan W, Klein M, et al. Neighborhood poverty and racial differences in ESRD incidence. J Am Soc Nephrol. 2008;19(2):356-64.

12. Patzer RE, Amaral S, Wasse H, Volkova N, Kleinbaum D, McClellan WM. Neighborhood poverty and racial disparities in kidney transplant waitlisting. J Am Soc Nephrol. 2009;20(6):1333-40. 
13. Merkin SS. Neighborhoods, race, and nephrology care. J Am Soc Nephrol. 2010;21(7):1068-70.

14. Rodriguez RA. Dialysis and mortality: does it matter where you live? Clin J Am Soc Nephrol. 2012;7(7):1055-7.

15. Hao H, Lovasik BP, Pastan SO, Chang HH, Chowdhury R, Patzer RE. Geographic variation and neighborhood factors are associated with low rates of pre-end-stage renal disease nephrology care. Kidney Int. 2015; 88(3):614-21.

16. Rodriguez RA, Sen S, Mehta K, Moody-Ayers S, Bacchetti P, O'Hare AM. Geography matters: relationships among urban residential segregation, dialysis facilities, and patient outcomes. Ann Intern Med. 2007;146(7): 493-501.

17. Yan G, Cheung AK, Ma JZ, et al. The associations between race and geographic area and quality-of-care indicators in patients approaching ESRD. Clin J Am Soc Nephrol. 2013;8(4):610-8.

18. Owen WF Jr, Chertow GM, Lazarus JM, Lowrie EG. Dose of hemodialysis and survival: differences by race and sex. JAMA. 1998;280(20):1764-8.

19. Choi Al, Rodriguez RA, Bacchetti P, Bertenthal D, Hernandez GT, O'Hare AM. White/black racial differences in risk of end-stage renal disease and death. Am J Med. 2009;122(7):672-8.

20. Agodoa L, Eggers P. Racial and ethnic disparities in end-stage kidney failuresurvival paradoxes in African-Americans. Semin Dial. 2007;20(6):577-85.

21. McClellan WM, Frederick PR, Helgerson SD, Hayes RP, Ballard DJ, McMullan M. A data-driven approach to improving the care of in-center hemodialysis patients. Health Care Financ Rev. 1995;16(4):129-40.

22. Golestaneh L, Bellin E, Neugarten J, Lo Y. Avoidable visits to the emergency department (ED) and their association with sex, age and race in a cohort of low socio-economic status patients on hemodialysis in the Bronx. PLoS One. 2018;13(8):e0202697.

23. Golestaneh L, Bellin E, Southern W, Melamed ML. Discharge service as a determinant of 30-day readmission in a cohort of maintenance hemodialysis patients: a retrospective cohort study. BMC Nephrol. 2017; 18(1):352.

24. United States Census Bureau. American Community Survey. https://www. census.gov/programs-surveys/acs. Accessed 15 Aug 2019.

25. Jakobsen JC, Gluud C, Wetterslev J, Winkel P. When and how should multiple imputation be used for handling missing data in randomised clinical trials - a practical guide with flowcharts. BMC Med Res Methodol. 2017;17(1):162.

26. Harel Z, Wald R, McArthur E, et al. Rehospitalizations and emergency department visits after hospital discharge in patients receiving maintenance hemodialysis. J Am Soc Nephrol. 2015;26(12):3141-50.

27. Lovasik BP, Zhang R, Hockenberry JM, et al. Emergency department use and hospital admissions among patients with end-stage renal disease in the United States. JAMA Intern Med. 2016;176(10):1563-5.

28. Komenda P, Tangri N, Klajncar E, et al. Patterns of emergency department utilization by patients on chronic dialysis: a population-based study. PLoS One. 2018;13(4):e0195323.

29. Charlson ME, Pompei P, Ales KL, Mackenzie CR. A new method of classifying prognostic comorbidity in longitudinal studies: development and validation. J Chronic Dis. 1987:40(5):373-83.

30. Assimon MM, Nguyen T, Katsanos SL, Brunelli SM, Flythe JE. Identification of volume overload hospitalizations among hemodialysis patients using administrative claims: a validation study. BMC Nephrol. 2016;17(1):173.

31. Arneson TJ, Liu J, Qiu Y, Gilbertson DT, Foley RN, Collins AJ. Hospital treatment for fluid overload in the Medicare hemodialysis population. Clin J Am Soc Nephrol. 2010;5(6):1054-63.

32. Thorpe RJ Jr, Norris KC, Beech BM, Bruce MA. In: Ford CL, Griffith DM, Bruce MA, Gilbert K, editors. "Racism across the life course." Is it race or racism?: state of the evidence \& tools for the public health professional. Washington, DC: APHA; 2019.

33. Yan G, Norris KC, Greene T, et al. Race/ethnicity, age, and risk of hospital admission and length of stay during the first year of maintenance hemodialysis. Clin J Am Soc Nephrol. 2014;9(8):1402-9.

34. Boulware LE, Cooper LA, Ratner LE, LaVeist TA, Powe NR. Race and trust in the health care system. Public Health Rep (Washington, DC: 1974). 2003; 118(4):358-65.

35. Institute of Medicine Committee on $U$, Eliminating $R$, Ethnic Disparities in Health C. In: Smedley BD, Stith AY, Nelson AR, editors. Unequal treatment: confronting racial and ethnic disparities in health care. Washington (DC):
National Academies Press (US) Copyright 2002 by the National Academy of Sciences. All rights reserved.; 2003.

36. Abdou CM, Fingerhut AW, Jackson JS, Wheaton F. Healthcare stereotype threat in older adults in the health and retirement study. Am J Prev Med. 2016;50(2):191-8.

37. Kucirka LM, Grams ME, Lessler J, et al. Association of race and age with survival among patients undergoing dialysis. JAMA. 2011;306(6):620-6.

38. Hammond WP, Matthews D, Mohottige D, Agyemang A, Corbie-Smith G. Masculinity, medical mistrust, and preventive health services delays among community-dwelling African-American men. J Gen Intern Med. 2010;25(12):1300-8.

\section{Publisher's Note}

Springer Nature remains neutral with regard to jurisdictional claims in published maps and institutional affiliations.
Ready to submit your research? Choose BMC and benefit from:

- fast, convenient online submission

- thorough peer review by experienced researchers in your field

- rapid publication on acceptance

- support for research data, including large and complex data types

- gold Open Access which fosters wider collaboration and increased citations

- maximum visibility for your research: over $100 \mathrm{M}$ website views per year

At BMC, research is always in progress.

Learn more biomedcentral.com/submissions 